\title{
Development of Split-Protein Systems: From Binary to Ternary System
}

\author{
Shengyi Shen \\ Department of Cellular and Molecular Medicine, University of Arizona, Tucson, AZ, USA \\ Email: shensy@email.arizona.edu
}

How to cite this paper: Shen, S.Y. (2021) Development of Split-Protein Systems: From Binary to Ternary System. Advances in Bios cience and Biotechnology, 12, 78-94. https://doi.org/10.4236/abb.2021.123006

Received: February 5, 2021

Accepted: March 23, 2021

Published: March 26, 2021

Copyright (c) 2021 by author(s) and Scientific Research Publishing Inc. This work is licensed under the Creative Commons Attribution International License (CC BY 4.0)

http://creativecommons.org/licenses/by/4.0/

\begin{abstract}
Tens of thousands of protein-protein interactions (PPIs) have been found in human cells and many of these macromolecular partnerships could determine the cell growth and death. Thus there is a need to develop the methods to catalogue these macromolecules by detecting their interactions, modifications, and cellular locations. It will be helpful for scientists to compare the difference between a diseased cellular state and its normal state and to find the potential therapy treatment to intervene this status. One technology called split-protein reassembly or protein fragment complementation has been developed in the last two decades. This technology makes use of appropriate fragmentation of some protein reporters and the refolding of these reports could be detected by their function to confirm the interaction of interest. This system has been set up in cell-free systems, E. coli, yeast, mammalian cells, plants and live animals. Herein, I present the development in fluorescenceand bioluminescence-based split-protein biosensors in both binary and ternary systems. In addition, some people developed the split-protein system by combining it with chemical inducer of dimerization strategy (CID). This has been applied for identifying the enzyme inhibitors and regulating the activity of protein kinases and phosphatases. With effort from many laboratories from the world, a variety of split-protein systems have been developed for studying the PPI in vitro and in vivo, monitoring the biological process, and controlling the activity of the enzyme of interest.
\end{abstract}

\section{Keywords}

Split-Protein Reassembly, Protein Fragment Complementation, Chemical Inducer of Dimerization (CID), Protein-Protein Interaction (PPI)

\section{Introduction}

In recent years, conditional split-protein reassembly has emerged as a method 
for the investigation of a variety of macromolecular interactions [1] [2] [3] [4]. In order to develop successful split-protein systems that can conditionally assemble and report upon the presence or absence of an interaction of interest, certain criteria have to be satisfied. Firstly, the parent protein or enzyme being fragmented to develop these types of sensors should have an easily measurable output, such as fluorescence or luminescence that is not significantly suppressed by other components in a cell or cell lysate. Secondly, the split protein fragments by themselves should not have any activity prior to reassembly. Thirdly, except for some self-assemble systems (such as GFP1-10/GFP11) [5], in the system for detecting protein-protein interactions (PPIs), the interaction between two protein fragments should be negligible ( $<100$ fold). For example, if the attached proteins being interrogated have a binding constant of $10 \mathrm{nM}$, then the split protein fragments should have a binding constant of $>1 \mu \mathrm{M}$ and ideally be reversible. The first conditional split protein reassembly system was established by Johnsson and Varshavsky in 1994 [6], where ubiquitin was split into two fragments and only regained its folded native structure when fused to two interacting protein domains. Since then many different proteins, mostly enzymes, have been engineered for developing split-protein reassembly systems, including the green fluorescent protein and its derivatives [5] [7] [8], dihydrofolate reductase [9], $\beta$-lactamase [10], firefly and other luciferases [11] [12] [13], tobacco etch virus protease [14], thymidine kinase [15], chorismate mutase [16], Cas9 [17], horseradish peroxidase [18], RNA polymerase [19], and aminoacyl tRNA synthetase [20]. Among these proteins, GFP and its variants, $\beta$-lacatamase, and firefly luciferase have been utilized as the reporter proteins for developing a wide range of sensors [21]-[33]. Herein, I will at first describe the development of split-protein systems which used fluorescence and bioluminescence as report signals and then focus on its extension to the ternary system for detecting the small molecules and macromolecules as well as controlling the activity of the enzymes of interest, such as protein kinase and phosphatase.

\section{Method}

Searched the manuscripts in Scopus with "Split protein reassembly" and "Protein fragment complementary". Obtain about 71 and 13,288 published papers. For the results from "Protein fragment complementary", searched the articles with "fluorescent protein" and "luciferase" respectively to obtain 1132 and 373 manuscripts. Read the title and abstract for these results and finally selected 165 and 80 manuscripts respectively for these two fields. The whole process is briefly described in Figure 1.

\section{Split-Protein Systems Based on Fluorescent Protein}

Green fluorescent protein (GFP) derived from Aequorea Victoria consists of a $\beta$-barrel structure with a central $\alpha$-helix. After folding to its native structure, three residues (S65-Y66-G67) in the central helix of GFP undergo autocatalysis 


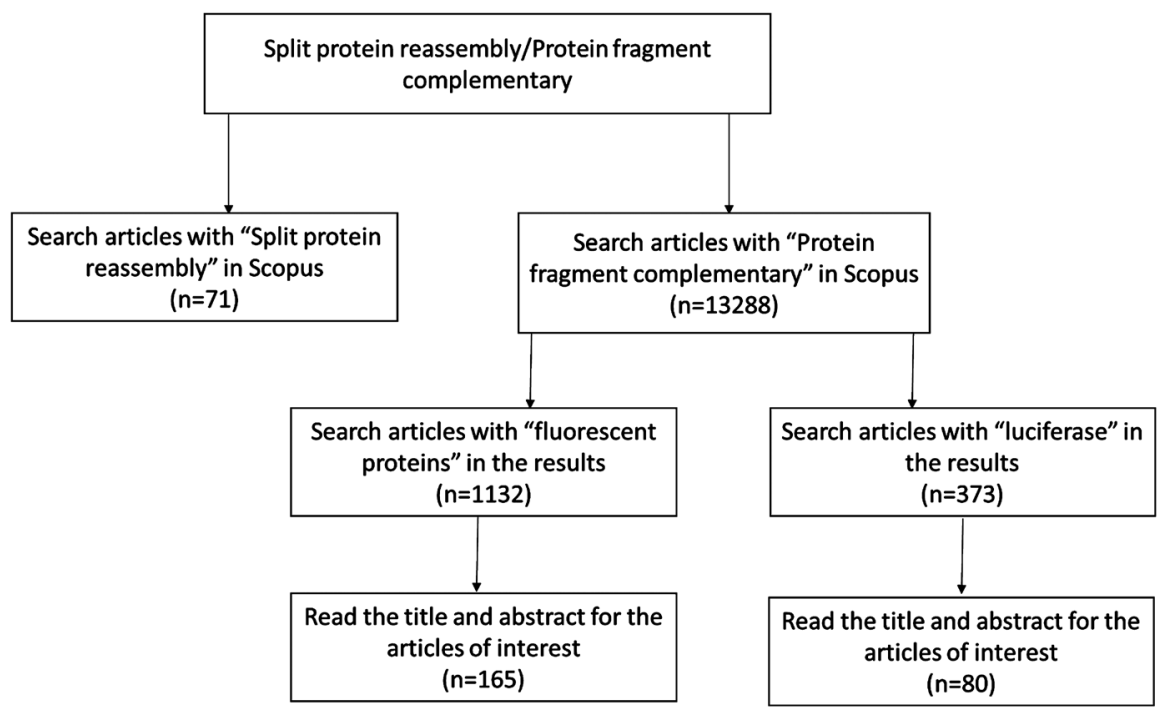

Figure 1. Flow chat of literature screening and selection process.

under oxidative conditions to yield the fluorophore. GFP and its variants have been attached to different proteins and protein-protein interactions are measured by fluorescence resonance energy transfer [34], however, this remains a demanding technique for routine applications [35] [36]. The first split-GFP was developed by dissection of the GFP protein at residues 157 and 158 and each fragment was fused to the heterodimeric leucine zippers, Fos and Jun, respectively [7]. It was shown that this was a conditional reassembly system as the native GFP protein was refolded in vitro and in E. coli only when Fos and Jun were present. This work was extended by Kerppola's group [8], which resulted in the split-YFP system, a yellow fluorescent GFP derivative, for the direct visualization of protein interactions in mammalian cells. Similarly, Furman extended this technique to many other Aequorea Victoria GFP variants, including GFPuv, Cerulean, EGFP, and Venus [33].

Following the discovery by Ghosh et al. many labs have greatly expanded the designs of different split-fluorescent proteins and the applications of this novel report system, where a unique name was given to this technology: bimolecular fluorescence complementation (BiFC). The reassembly of fluorescent proteins in the most of these designs was demonstrated to be irreversible under native conditions, that is when the native structure of fluorescent protein was conditionally reconstituted then this structure was resistant to dissociation. This kinetic effect might be particularly helpful for the detection of low abundance or low affinity complexes in vivo and in vitro [37] [38] but is a major problem with regard to the misinterpretation of PPIs and careful control experiments with known mutations that prevent binding need to be routinely carried out [34] [39] [40]. Moreover, many laboratories are interested in disrupting PPIs with peptides and small molecules [10] [11] [13], which can also be difficult to accomplish and interpret in these systems that are not under thermodynamic control. To address this problem, two labs have achieved some advancement with two specific sys- 
tems. Tchekanda et.al developed one reversible BiFC based on the engineered $D$. radiodurans infrared fluorescent protein IFP1.4 (using biliverdin as its chromophore) [41]. They have demonstrated the reversibility of this probe in vitro and applied this system in yeast and mammalian cells. To et al. engineered a reversible green split protein reporter, named uPPO [UnaG-based protein-protein interaction reporter] where after refolding UnaG protein could incorporate bilirubin as the chromophore in mammalian cells [42]. Although both of these two systems require the incorporation of chromophores, they supplied one methodology to design the reversible BiFC system, which has great potential application to study the dynamics of PPIs with low background signals.

In addition to the reversibility issue, there are some other limitations in the applications for BiFC system. First, the long maturation time for the chromophore formation during the refolding process, which caused the unavoidable delay between the PPIs and the signal readout. Second, the nonspecific self-reassembly of the two fragments could increase the background signals. Moreover, the solubility of the split fragments and its fusion protein could also perturb the application of this technology. To solve these problems, Cabantous et al. firstly designed one GFP1-10/GFP11 system [5] based on their well-designed superfolder GFP protein (sfGFP), which has 11 mutations compared with avGFP protein and has high folding stability in the solution [43]. This system has been used for detecting the solubility of proteins of interest by their self-reassembly of these two fragments [44]. Then it was widely used as a sensor for detecting the activity of protease [45] [46] [47], protein kinase and phosphatase [48], and other peptides or cargoes penetrating the cells [49] [50] [51]. Furthermore, Cabantous et al. modified this system to create a tripartite split GFP system consisting three fragments (GFP1-9, GFP10, and GFP11) [52]. Compared with the previous GFP system, the domains chosen to fusing other protein binding partners (GFP10 and GFP11) have much less perturbance to the proteins of interest and avoid the aggregation problems. More importantly, this system minimizes the background signals from self-assembly. This novel split GFP system has not only been used for developing the sensors for small GTPases and sortase [53] [54] but also found able to promote the crystallization of the protein [55] [56].

\section{Split-Protein Systems Based on Luciferase}

On the other hand, following the discovery of split-GFP and its variants, firefly and other luciferases have also been developed as reporters using split-protein systems [11] [12] [13] (Table 1). Luciferases produce a luminescent signal by catalyzing the oxidation reaction of small molecule substrates, which does not need input of light and has very low background signal. Moreover, the dynamic study of protein-protein interaction through split-luciferase systems in vitro and in vivo showed that split-luciferase was a reversal and sensitive reporter at endogenous protein expression levels [11].

Due to the excellent advantages of bioluminescence-based split protein systems, some labs have developed sensors for visualizing dynamic process of the PPIs 
Table 1. List of the reference for different proteins as reporters in Split-protein reassembly technology.

\begin{tabular}{cc}
\hline Reference type & Reference number \\
\hline Split protein reassembly with Fluorescent protein as reporter & {$[5][6][7][8][21][22][33]$} \\
Split protein reassembly with luciferase as reporter & {$[37]-[42][44]-[56]$} \\
Split protein reassembly with dihydrofolate reductase & {$[12][13][24]-[32][57]-[71]$} \\
Split protein reassembly with $\beta$-lactamase & {$[10][23]$} \\
Split protein reassembly with tobacco etch virus protease & {$[14]$} \\
Split protein reassembly with thymidine kinase & {$[15]$} \\
Split protein reassembly with chorismate mutase & {$[16]$} \\
Split protein reassembly with Cas9 & {$[17]$} \\
Split protein reassembly with horseradish peroxidase & {$[18]$} \\
Split protein reassembly with RNA polymerase & {$[19]$} \\
Split protein reassembly with aminoacyl tRNA synthetase & {$[20]$} \\
Split protein reassembly with kinase & {$[89]$} \\
Split protein reassembly with phosphatase & {$[90]$}
\end{tabular}

during the cell signaling pathway. Paulmurugan et al. firstly inserted the estrogen receptor (ER) ligand binding domain into Renilla luciferase or firely luciferase, which was used for imaging ligand-induced intramolecular folding in living mice [57]. Following this study, several biosensors have been developed to detect the effect of mutations in human ER $\alpha$ [58], obtain the simultaneous detection of different ligand actions on ER [59] [60], and the dimerization of two types of ER (ER $\alpha$ and $\mathrm{ER} \beta$ ) [61]. In other fields, split-luciferase system has also been used for investigating the Myc protein [62] [63], the Notch receptor [64] [65], EGFP and its mutants [66] [67], interaction of G-protein-coupled receptor with $\beta$-arrestins [68] [69], and ErbB2/HER2/neu pathway [70].

In addition to in vivo assays, there has been also a great development for a large number of in vitro cell-free expression systems for measuring a variety of different macromolecular interactions using split luciferase reporter systems which showed the advantages in both ease of detection and sensitivity [24]-[32]. In cell-free methods, the mRNA of split-luciferase fused with a designed protein binding domain of interest are obtained by in vitro transcription, and after purification, the fused split-luciferase fragments are translated from the mRNA in cell-lysates in vitro. The translated split-protein fragments can undergo reassembly to its native and active form, either by PPI in binary systems or by addition of the target for the two fused protein binding domains in ternary systems.

\section{Ternary Split-Protein Sensors: Beyond Binary Interactions}

Although binary split-protein systems have been widely used for the study of 
PPIs in vitro and in vivo, the ternary split-protein systems with high sensitivity for the targets have been systematically developed over the past decade (Figure 2). Compared with the binary system which made use of two interacting protein domains fused to the split-reporter protein fragments, in the ternary system, two protein binding domains with limited interaction are fused to the split-GFP or split-luciferase domains. With the addition of the target or analyte of interest, the interaction between the protein binding domains with the analyte molecule brings the two fragments of the reporter protein in proximity, which enables the refolding of the native protein which regains activity for readout of the analyte of interest.

\subsection{Sensors for Nucleic Acids and Its Modifications}

Stains et al creatively designed one novel reporter in which two split-GFP fragments were fused to the designed and natural Cys2-His2 zinc finger DNA binding domains [21]. In the presence of target DNA, the two GFP domains were brought into close proximity and shown to refold and fluoresce only when specific adjacent DNA sites were available for both the zinc finger domains. Later on, this system was extended by replacing the reporter protein with other GFP variants for simultaneous detection of multiple targets [33], $\beta$-lactamase [23] or firefly luciferase [24] for improved sensitivity. The ternary system was shown to

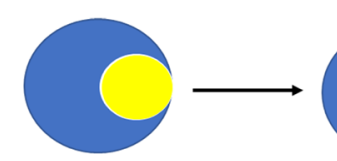

Active reporter protein

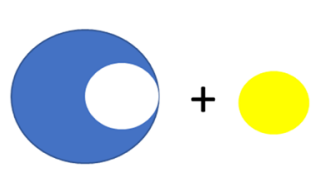

Inactive split protein fragments

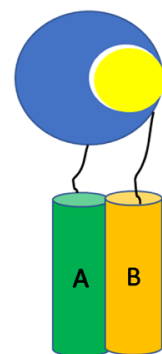

In binary system, two domains interact with each other to reassemble the reporter protein

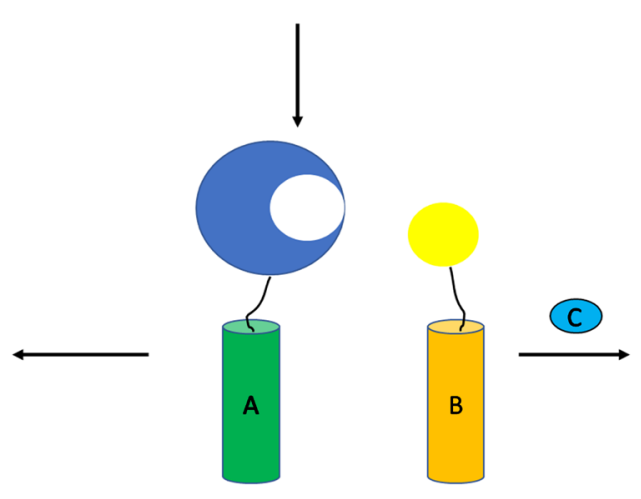

Split reporter fragments fused to domains of interest

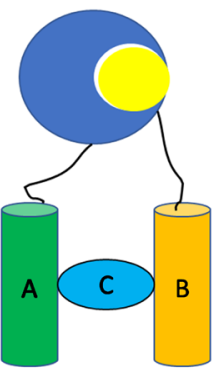

In ternary system, two domains interact with the third domain to reassemble the reporter protein

Figure 2. Split protein reassembly/Protein fragment complementary method in binary system and ternary system. Reporter protein is divided into two fragments which could regain the function of the whole protein after reassembly under some condition. These two fragments are fused to the domains of interest (A and B). In binary system, the interaction of these two domains could bring the two reporter fragments close enough for the protein refolding (bottom left). In the ternary system, these two domains could form complex by binding the third domain $(C)$ in the solution, which enables the reassembly of the reporter protein. 
be a general approach for detecting DNA modifications by modulation of the protein binding domain [22] [23] [30] [31]. In these systems, the zinc finger domains were replaced by alternate binding domains that target specific nucleic acid modifications. For instance, methyl binding domain (MBD) that binds methylated cytosines and Zif268, a natural zinc finger domain, have been used in the split-protein system for the detection of specific sites of DNA methylation [22] a known epigenetic modification. Furthermore, they also systematically investigated the difference between different MBD family members and their ability to recognize methylated DNA [31].

The cell-free split luciferase system has also been adapted for designing turn-on sensors for UV or oxidation-dependent DNA damage. In this design, oxoguanine glycosylase 1 (OGG1) or the damaged-DNA binding domain 2 (DDB2) was fused to the C-terminal fragment of firefly luciferase (CFluc) while MBD was fused to the N-terminal fragment of firefly luciferase (NFluc) [30]. With conjugation of the protein domain with corresponding specific DNA modification site, the split-firefly luciferase was shown to reassemble. This sensor provided a simple and sensitive approach for the rapid detection of the chemical modification of DNA exposed to different environmental insults.

Compared with the detection of DNA, few strategies have been developed for detection of specific RNA sequence due to the limitation of RNA recognition domains. To overcome this difficulty, three kinds of strategies with split-protein reassembly have been developed [24] [27]. The earliest one was to make use of the protein-target interaction directly, where Pumilio (Pum) RNA binding proteins confer specificity for binding a particular ssRNA sequencing.

To develop general strategy for sequence-specifically assembling for any user-defined ssRNA target, Argonaute (Ago), which has been found able to bind to the 2-nucleotide, 3' overhangs of short double stranded RNA (dsRNA), was utilized for the target binding site. To obtain the binding with Ago domain, dsRNA was prepared by addition of complementary guide oligonucleotides which could target the ssRNA sample in the solution. As a third design, dsDNA hairpins were combined with ssRNA guides which were complementary to the ssRNA target. In this method, high affinity (Kd $\sim$ low $\mathrm{pM}$ ) of sequence-specific Zinc finger domains were fused to the slit-luciferase, and the specific sensor could be designed flexibly by replacing the complementary ssRNA sequence for the target ssRNA of interest.

\subsection{Sensor for Native Proteins}

The direct and specific detection of native proteins in complex heterogeneous solution remains a challenge. Then, a general methodology based on the splitluciferase system was developed by combining single-chain antibodies or cellular receptor fragments that target specific native proteins of interest [28]. This method was used for the detection of vascular endothelial growth factor (VEGF), gp120 and human epidermal growth factor receptor-2 (HER2). The requirement 
for this strategy is that the two binding domains of the split-luciferase system should be able to bind the target protein simultaneously at different sites which should be close enough to allow for the reassembly of the reporter protein. More importantly, as shown in the recognition of HER2, the single-strand antibodies which were translated in vitro system could extend this technique to other application with an entirely antibody-based recognition system.

\subsection{Sensor for Protein Modification}

After translation of proteins from ribosome, there are various post-translational modifications on proteins, which play an important role in the protein folding, location, and its function. There is one post-translational modification of proteins with a polymer, poly (ADP- ribose) or PAR, which is involved in the DNA damage repair process [71]. Furman et al. designed one split-luciferase system for the detecting this post-translational modification by fusing the two split luciferase fragments to the PBZ domains deriving from Aprataxin and PNK-lik factor (APLF) [72], which has been shown strong binding affinity to PAR [73]. This split-protein report has been applied for both monitoring temporal changes of poly(ADP-ribosyl)ation in mammalian cells and detecting the activity of poly (ADP-ribose) glycohydrolase in vitro, which degrades PAR in cells.

\subsection{Chemically Induced Dimerization Based Split-Luciferase Systems}

Since the discovery of rapamycin-induced heterodimerization of FKBP12 (FK506 binding protein) with FRB (FKBP12 rapamycin binding protein) [74], a methodology that is now called chemically inducer of dimerization strategy or CID, has been developed where two non-interacting fusion proteins, with affinity for a ligand or hybrid ligand, are brought together in presence of a ligand to perform a specific function [75]. CID has been proved powerful, and small ligands have been used for controlling cellular localization [76] [77] [78] [79], inducing protein splicing [80] [81] [82], selectively labeling proteins, targeting them for destruction [83] [84] [85], and to probe various cellular functions.

Based on the concepts of split-protein complementation and CID, a coiled-coil peptide enabled split-luciferase system was developed by Jester et al. for the detection of inhibitors of protein kinases (Figure 3) [26] [29]. In this system, the CFluc domain was fused to the protein kinase of interest and the NFluc domain was fused to Fos peptide. Without addition of the ligand, there was limited interaction between the two protein fragments after in vitro translation. A chemical inducer of dimerization, Jun-staurosporine was designed based on the fact that Fos/Jun peptides interaction has high specificity and affinity and staurosporine is a pan kinase inhibitor. In the presence of the inducer, Jun-staurosporine, the two split luciferase domains were found able to reassemble and regain the enzyme function. The reversibility of this formation made it possible that this ternary could be disrupted by the addition of small molecule kinase inhibitors, which could bind the protein kinase at the same binding site as staurosporine. 


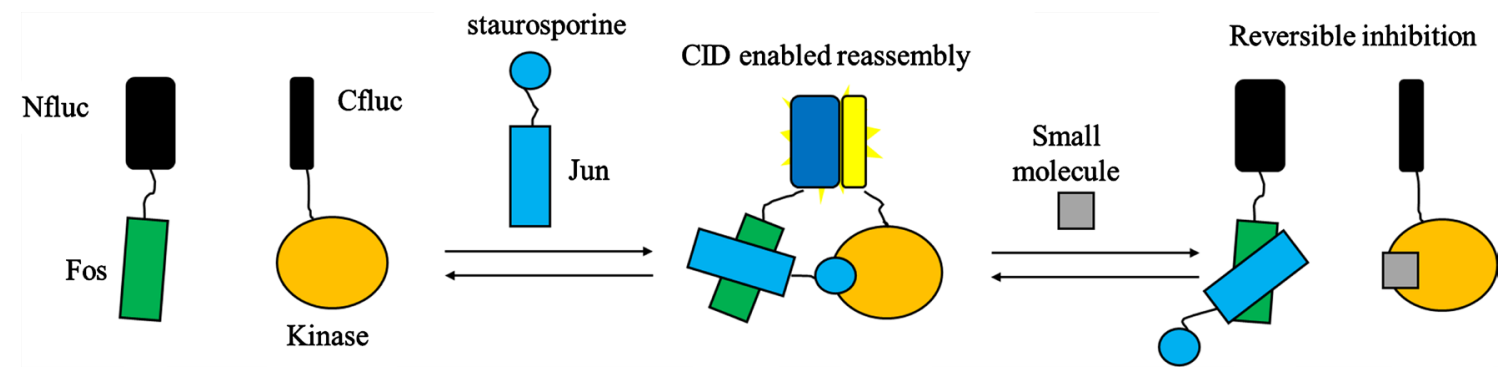

Figure 3. Coiled-coil enabled CID system for profiling inhibitors of protein kinases [26]. Split firefly luciferase fragments were fused to protein kinase and one coiled-coil peptide (Fos). With the addition of Jun-staurosporine, the firefly luciferase could be reassembled with inducer, which could be perturbed by binding the new inhibitors on the ATP-binding site in protein kinase.

The decrease of the luminescence due to the disruption by small molecule was found to be dose-dependent and the observed signal loss followed a characteristic sigmoidal curve, with which an IC50 of the inhibitor could be measured and was found to be similar to those measured by traditional radioactivity based kinase assays.

\subsection{Chemically Induced Dimerization Based Split-Kinase and Split-Phosphatase Systems}

Post-translational modifications control the temporal and location specific activity of most proteins. In these chemical modifications, phosphorylation and dephosporylation play important roles in the regulation of a diversity of cellular events [86]. Over 500 human protein kinases and 147 protein phosphatases are the key cues in both intra- and extracellular studies [87] [88]. Recently CID technology has successfully achieved the reassembly of split-kinase [89] and split-tyrosine phosphatases [90] with FKBP and FRB, where catalytic activity of kinase or phosphatase could be modulated with rapamycin. In addition, Camacho-Soto et al. also confirmed that the rapamycin gated FKBP/FRB heterodimer could be replaced by two plant-hormone based CID systems [90], which provided a pathway to the small molecule activation of specific split-phosphatase or split-kinase without perturbing cellular signaling in mammalian cell systems.

\section{Outlook and Conclusion}

With the development of split-protein reassembly, it could be predicted that there will be more biological activities and biomolecular processes which could be monitored in vitro or in vivo. There has been a variety of applications based on split-protein reassembly and the long-term potential of this methodology is exciting and has been achieving more and more attention. People have achieved the ability to detect binary and ternary partnerships and the rapid interrogation of small molecules that perturb them. The expanding repertoire of split-proteins supplies a means for the temporal control over the outcome of thousands of biomolecular processes. This has already enabled the explicit control over the outcome of one specific signal transduction pathway with this technology, such 
as the protein kinases and phosphatases. Finally, it can be envisioned that the general split-protein ternary system approach may provide new therapeutic and imaging methods with the conditional reassembly of a split toxic protein in the specific cells.

\section{Conflicts of Interest}

The author declares no conflicts of interest regarding the publication of this paper.

\section{References}

[1] Kerppola, T.K. (2009) Visualization of Molecular Interactions Using Bimolecular Fluorescence Complementation Analysis: Characteristics of Protein Fragment Complementation. Chemical Society Reviews, 38, 2876-2886.

https://doi.org/10.1039/b909638h

[2] Lalonde, S., Ehrhardt, D.W., Loque, D., Chen, J., Rhee, S.Y. and Frommer, W.B. (2008) Molecular and Cellular Approaches for the Detection of Protein-Protein Interactions: Latest Techniques and Current Limitations. The Plant Journal, 53, 610-635. https://doi.org/10.1111/j.1365-313X.2007.03332.x

[3] Shekhawat, S.S. and Ghosh, I. (2011) Split-Protein Systems: Beyond Binary Protein-Protein Interactions. Current Opinion in Chemical Biology, 15, 789-797. https://doi.org/10.1016/j.cbpa.2011.10.014

[4] Ventura, S. (2011) Bimolecular Fluorescence Complementation: Illuminating Cellular Protein Interactions. Current Molecular Medicine, 11, 582-598. https://doi.org/10.2174/156652411800615117

[5] Cabantous, S., Thomas, C.T. and Waldo, G.S. (2005) Protein Tagging and Detection with Engineered Self-Assembling Fragments of Green Fluorescent Protein. Nature Biotechnology, 23, 102-107. https://doi.org/10.1038/nbt1044

[6] Johnsson, N. and Varshavsky, A. (1994) Split Ubiquitin as a Sensor of Protein Interactions in Vivo. Proceedings of the National Academy of Sciences of the United States of America, 91, 10340-10344. https://doi.org/10.1073/pnas.91.22.10340

[7] Ghosh, I., Hamilton, A.D. and Regan, L. (2000) Antiparallel Leucine Zipper-Directed Protein Reassembly: Application to the Green Fluorescent Protein. Journal of the American Chemical Society, 122, 5658-5659. https://doi.org/10.1021/ja994421w

[8] Hu, C.D. and Kerppola, T.K. (2003) Simultaneous Visualization of Multiple Protein Interactions in Living Cells Using Multicolor Fluorescence Complementation Analysis. Nature Biotechnology, 21, 539-545. https://doi.org/10.1038/nbt816

[9] Pelletier, J.N., Campbell-Valois, F.X. and Michnick, S.W. (1998) Oligomerization Domain-Directed Reassembly of Active Dihydrofolate Reductase from Rationally Designed Fragments. Proceedings of the National Academy of Sciences of the United States of America, 95, 12141-12146. https://doi.org/10.1073/pnas.95.21.12141

[10] Galarneau, A., Primeau, M., Trudeau, L.E. and Michnick, S.W. (2002) $\beta$-Lactamase Protein Fragment Complementation Assays as in Vivo and in Vitro Sensors of Protein-Protein Interactions. Nature Biotechnology, 20, 619-622. https://doi.org/10.1038/nbt0602-619

[11] Luker, K.E., Smith, M.C. P., Luker, G.D., Gammon, S.T., Piwnica-Worms, H. and Piwnica-Worms, D.P. (2004) Kinetics of Regulated Protein-Protein Interactions Revealed with Firefly Luciferase Complementation Imaging in Cells and Living 
Animals. Proceedings of the National Academy of Sciences of the United States of America, 101, 12288-12293. https://doi.org/10.1073/pnas.0404041101

[12] Paulmurugan, R. and Gambhir, S.S. (2003) Monitoring Protein-Protein Interactions Using Split Synthetic Renilla Luciferase Protein-Fragment-Assisted Complementation. Analytical Chemistry, 75, 1584-1589. https://doi.org/10.1021/ac020731c

[13] Remy, I. and Michnick, S.W. (2006) A Highly Sensitive Protein-Protein Interaction Assay Based on Gaussia Luciferase. Nature Methods, 3, 977-979. https://doi.org/10.1038/nmeth979

[14] Wehr, M.C., Laage, R., Bolz, U., Fischer, T.M., Grunewald, S., Scheek, S., Bach, A., Nave, K.A. and Rossner, M.J. (2006) Monitoring Regulated Protein-Protein Interactions using Split TEV. Nature Methods, 3, 985-993. https://doi.org/10.1038/nmeth967

[15] Massoud, T.F., Paulmurugan, R. and Gambhir, S.S. (2010) A Molecularly Engineered Split Reporter for Imaging Protein-Protein Interactions with Positron Emission Tomography. Nature Medicine, 16, 921-926. https://doi.org/10.1038/nm.2185

[16] Muller, M.M., Kries, H., Csuhai, E., Kast, P. and Hilvert, D. (2010) Design, Selection, and Characterization of a Split Chorismate Mutase. Protein Science, 19, 1000-1010. https://doi.org/10.1002/pro.377

[17] Zetsche, B., Volz, S.E. and Zhang, F. (2015) A Split-Cas9 Architecture for Inducible Genome Editing and Transcription Modulation. Nature Biotechnology, 33, 139-142. https://doi.org/10.1038/nbt.3149

[18] Martell, J.D., Yamagata, M., Deerinck, T.J., Phan, S., Kwa, C.G., Ellisman, M.H., Sanes, J.R. and Ting, A.Y. (2016) A Split Horseradish Peroxidase for the Detection of Intercellular Protein-Protein Interactions and Sensitive Visualization of Synapses. Nature Biotechnology, 34, 774-780. https://doi.org/10.1038/nbt.3563

[19] Pu, J., Zinkus-Boltz, J. and Dickinson, B.C. (2017) Evolution of a Split RNA Polymerase as a Versatile Biosensor Platform. Nature Chemical Biology, 13, 432-438. https://doi.org/10.1038/nchembio.2299

[20] Thomas, E.E., Pandey, N., Knudsen, S., Ball, Z.T. and Silberg, J.J. (2017) Programming Post-Translational Control over the Metabolic Labeling of Cellular Proteins with a Noncanonical Amino Acid. ACS Synthetic Biology, 6, 1572-1583. https://doi.org/10.1021/acssynbio.7b00100

[21] Stains, C.I., Porter, J.R., Ooi, A.T., Segal, D.J. and Ghosh, I. (2005) DNA Sequence-Enabled Reassembly of the Green Fluorescent Protein. Journal of the American Chemical Society, 127, 10782-10783. https://doi.org/10.1021/ja051969w

[22] Stains, C.I., Furman, J.L., Segal, D.J. and Ghosh, I. (2006) Site-Specific Detection of DNA Methylation Utilizing mCpG-SEER. Journal of the American Chemical Society, 128, 9761-9765. https://doi.org/10.1021/ja060681j

[23] Porter, J.R., Stains, C.I., Segal, D.J. and Ghosh, I. (2007) Split $\beta$-Lactamase Sensor for the Sequence-Specific Detection of DNA Methylation. Analytical Chemistry, 79, 6702-6708. https://doi.org/10.1021/ac071163+

[24] Porter, J.R., Stains, C.I., Jester, B.W. and Ghosh, I. (2008) A General and Rapid Cell-Free Approach for the Interrogation of Protein-Protein, Protein-DNA, and Protein-RNA Interactions and their Antagonists Utilizing Split-Protein Reporters. Journal of the American Chemical Society, 130, 6488-6497. https://doi.org/10.1021/ja7114579

[25] Shekhawat, S.S., Porter, J.R., Sriprasad, A. and Ghosh, I. (2009) An Autoinhibited Coiled-Coil Design Strategy for Split-Protein Protease Sensors. Journal of the 
American Chemical Society, 131, 15284-15290. https://doi.org/10.1021/ja9050857

[26] Jester, B.W., Cox, K.J., Gaj, A., Shomin, C.D., Porter, J.R. and Ghosh, I. (2010) A Coiled-Coil Enabled Split-Luciferase Three-Hybrid System: Applied Toward Profiling Inhibitors of Protein Kinases. Journal of the American Chemical Society, 132, 11727-11735. https://doi.org/10.1021/ja104491h

[27] Furman, J.L., Badran, A.H., Ajulo, O., Porter, J.R., Stains, C.I., Segal, D.J. and Ghosh, I. (2010) Toward a General Approach for RNA-Templated Hierarchical Assembly of Split-Proteins. Journal of the American Chemical Society, 132, 11692-11701. https://doi.org/10.1021/ja104395b

[28] Stains, C.I., Furman, J.L., Porter, J.R., Rajagopal, S., Li, Y.X., Wyatt, R.T. and Ghosh, I. (2010) A General Approach for Receptor and Antibody-Targeted Detection of Native Proteins Utilizing Split-Luciferase Reassembly. ACS Chemical Biology, 5, 943-952. https://doi.org/10.1021/cb100143m

[29] Jester, B.W., Gaj, A., Shomin, C.D., Cox, K.J. and Ghosh, I. (2012) Testing the Promiscuity of Commercial Kinase Inhibitors against the AGC Kinase Group Using a Split-Luciferase Screen. Journal of Medicinal Chemistry, 55, 1526-1537. https://doi.org/10.1021/jm201265f

[30] Furman, J.L., Mok, P.W., Badran, A.H. and Ghosh, I. (2011) Turn-On DNA Damage Sensors for the Direct Detection of 8-Oxoguanine and Photoproducts in Native DNA. Journal of the American Chemical Society, 133, 12518-12527. https://doi.org/10.1021/ja1116606

[31] Badran, A.H., Furman, J.L., Ma, A.S., Comi, T.J., Porter, J.R. and Ghosh, I. (2011) Evaluating the Global CpG Methylation Status of Native DNA Utilizing a Bipartite Split-Luciferase Sensor. Analytical Chemistry, 83, 7151-7157. https://doi.org/10.1021/ac2015239

[32] Porter, J.R., Helmers, M.R., Wang, P., Furman, J.L., Joy, S.T., Arora, P.S. and Ghosh, I. (2010) Profiling Small Molecule Inhibitors against Helix-Receptor Interactions: The Bcl-2 Family Inhibitor BH3I-1 Potently Inhibits p53/hDM2. Chemical Communications, 46, 8020-8022. https://doi.org/10.1039/c0cc02969f

[33] Furman, J.L., Badran, A.H., Shen, S.Y., Stains, C.I., Hannallah, J., Segal, D.J. and Ghosh, I. (2009) Systematic Evaluation of Split-Fluorescent Proteins for the Direct Detection of Native and Methylated DNA. Bioorganic \& Medicinal Chemistry Letters, 19, 3748-3751. https://doi.org/10.1016/j.bmcl.2009.04.141

[34] Zhang, J., Campbell, R.E., Ting, A.Y. and Tsien, R.Y. (2002) Creating New Fluorescent Probes for Cell Biology. Nature Reviews Molecular Cell Biology, 3, 906-918. https://doi.org/10.1038/nrm976

[35] Ozawa, T., Kaihara, A., Sato, M., Tachihara, K. and Umezawa, Y. (2001) Split Luciferase as an Optical Probe for Detecting Protein-Protein Interactions in Mammalian Cells Based on Protein Splicing. Analytical Chemistry, 73, 2516-2521. https://doi.org/10.1021/ac0013296

[36] Wehrman, T., Kleaveland, B., Her, J.H., Balint, R.F. and Blau, H.M. (2002) Protein-Protein Interactions Monitored in Mammalian Cells via Complementation of $\beta$-Lactamase Enzyme Fragments. Proceedings of the National Academy of Sciences of the United States of America, 99, 3469-3474.

https://doi.org/10.1073/pnas.062043699

[37] Avitabile, E., Forghieri, C. and Campadelli-Fiume, G. (2007) Complexes between Herpes Simplex Virus Glycoproteins gD, gB, and gH Detected in Cells by Complementation of Split Enhanced Green Fluorescent Protein. Journal of Virology, 81, 11532-11537. https://doi.org/10.1128/JVI.01343-07 
[38] Morell, M., Espargaró, A., Avilés, F.X. and Ventura, S. (2007) Detection of Transient Protein-Protein Interactions by Bimolecular Fluorescence Complementation: The Abl-SH3 Case. Proteomics, 7, 1023-1036. https://doi.org/10.1002/pmic.200600966

[39] Magliery, T.J., Wilson, C.G.M., Pan, W.L., Mishler, D., Ghosh, I., Hamilton, A.D. and Regan, L. (2005) Detecting Protein-Protein Interactions with a Green Fluorescent Protein Fragment Reassembly Trap: Scope and Mechanism. Journal of the American Chemical Society, 127, 146-157. https://doi.org/10.1021/ja046699g

[40] Hu, C.D., Chinenov, Y. and Kerppola, T.K. (2002) Visualization of Interactions among bZIP and Rel Family Proteins in Living Cells Using Bimolecular Fluorescence Complementation. Molecular Cell, 9, 789-798.

https://doi.org/10.1016/S1097-2765(02)00496-3

[41] Tchekanda, E., Sivanesan, D. and Michnick, S.W. (2014) An Infrared Reporter to Detect Spatiotemporal Dynamics of Protein-Protein Interactions. Nature Methods, 11, 641-644. https://doi.org/10.1038/nmeth.2934

[42] To, T.L., Zhang, Q. and Shu, X. (2016) Structure-Guided Design of a Reversible Fluorogenic Reporter of Protein-Protein Interactions. Protein Science, 25, 748-753. https://doi.org/10.1002/pro.2866

[43] Pedelacq, J.D., Cabantous, S., Tran, T., Terwilliger, T.C. and Waldo, G.S. (2006) Engineering and Characterization of a Superfolder Green Fluorescent Protein. Nature Biotechnology, 24, 79-88. https://doi.org/10.1038/nbt1172

[44] Cabantous, S. and Wald, G.S. (2006) In Vivo and in Vitro Protein Solubility Assays Using Split GFP. Nature Methods, 3, 845-854. https://doi.org/10.1038/nmeth932

[45] Callahan, B.P., Stanger, M.J. and Belfort, M. (2010) Protease Activation of Split Green Fluorescent Protein. ChemBioChem, 11, 2259-2263. https://doi.org/10.1002/cbic.201000453

[46] Sakamoto, S., Terauchi, M., Hugo, A., Kim, T., Araki, Y. and Wada, T. (2013) Creation of a Caspase-3 Sensing System Using a Combination of Split-GFP and Split-Intein. Chemical Communications, 49, 10323-10325. https://doi.org/10.1039/c3cc43389g

[47] To, T.L., Schepis, A., Ruiz-Gonzalez, R., Zhang, Q., Yu, D., Dong, Z., Coughlin, S. R. and Shu, X. (2016) Rational Design of a GFP-Based Fluorogenic Caspase Reporter for Imaging Apoptosis in Vivo. Cell Chemical Biology, 23, 875-882. https://doi.org/10.1016/j.chembiol.2016.06.007

[48] Yin, C., Wang, M., Lei, C., Wang, Z., Li, P., Li, Y., Li, W., Huang, Y., Nie, Z. and Yao, S. (2015) Phosphorylation-Mediated Assembly of a Semisynthetic Fluorescent Protein for Label-Free Detection of Protein Kinase Activity. Analytical Chemistry, 87, 6311-6318. https://doi.org/10.1021/acs.analchem.5b01160

[49] Milech, N., Longville, B.A.C., Cunningham, P.T., Scobie, M.N., Bogdawa, H.M., Winslow, S., Anastasas, M., Connor, T., Ong, F., Stone, S.R., Kerfoot, M., Heinrich, T., Kroeger, K.M., Tan, Y., Hoffmann, K., Thomas, W.R., Watt, P.M. and Hopkins, R.M. (2015) GFP-Complementation Assay to Detect Functional CPP and Protein Delivery into Living Cells. Scientific Report, 5, Article No. 18329.

https://doi.org/10.1038/srep18329

[50] Park, E., Lee, H.Y., Woo, J., Choi, D. and Dinesh-Kuma, S.P. (2017) Spatiotemporal Monitoring of Pseudomonas syringae Effectors via Type III Secretion Using Split Fluorescent Protein Fragments. Plant Cell, 29, 1571-1584.

https://doi.org/10.1105/tpc.17.00047

[51] Schmit, S., Adjobo-Hermans, M.J., Wallbrecher, R., Verdurmen, W.P., Bovée-Geurts, P.H.M., van Oostrum, J., Milletti, F., Enderle, T. and Brock, R. (2015) Detecting 
Cytosolic Peptide Delivery with the GFP Complementation Assay in the Low Micromolar Range. Angewandte Chemie International Edition, 54, 15105-15108. https://doi.org/10.1002/anie.201505913

[52] Cabantous, S., Nguyen, H.B., Pédelacq, J.D., Koraichi, F., Chaudhary, A., Ganguly, K., Lockard, M.A., Favre, G., Terwilliger, T.C. and Waldo, G.S. (2013) A New Protein-Protein Interaction Sensor Based on Tripartite Split-GFP Association. Scientific Reports, 3, Article No. 2854. https://doi.org/10.1038/srep02854

[53] Koraïchi, F., Gence, R., Bouchenot, C., Grosjean, S., Lajoie-Mazenc, I., Favre, G. and Cabantous, S. (2018) High-Content Tripartite Split-GFP Cell-Based Assays to Screen for Modulators of Small GTPase Activation. Journal of Cell Science, 131, Article ID: jcs210419. https://doi.org/10.1242/jcs.210419

[54] Zhang, J., Wang, M., Tang, R., Liu, Y., Lei, C., Huang, Y., Nie, Z. and Yao, S. (2018) Transpeptidation-Mediated Assembly of Tripartite Split Green Fluorescent Protein for Label-Free Assay of Sortase Activity. Analytical Chemistry, 90, 3245-3252. https://doi.org/10.1021/acs.analchem.7b04756

[55] Leibly, D.J., Arbing, M.A., Pashkov, I., De Vore, N., Waldo, G.S., Terwilliger, T.C. and Yeates, T.O. (2015) A Suite of Engineered GFP Molecules for Oligomeric Scaffolding. Structure, 23, 1754-1768. https://doi.org/10.1016/j.str.2015.07.008

[56] Nguyen, H.B., Hung, L.W., Yeates, T.O., Terwilliger, T.C. and Waldo, G.S. (2013) Split Green Fluorescent Protein as a Modular Binding Partner for Protein Crystallization. Acta Crystallographic Section D, 69, 2513-2523. https://doi.org/10.1107/S0907444913024608

[57] Paulmurugan, R. and Gambhir, S.S. (2006) An Intramolecular Folding Sensor for Imaging Estrogen Receptor-Ligand Interactions. Proceedings of the National Academy of Sciences of the United States of America, 103, 15883-15888. https://doi.org/10.1073/pnas.0607385103

[58] Paulmurugan, R., Tamrazi, A., Katzenellenbogen, J.A., Katzenellenbogen, B.S. and Gambhir, S.S. (2008) A Human Estrogen Receptor (ER) a Mutation with Differential Responsiveness to Nonsteroidal Ligands: Novel Approaches for Studying Mechanism of ER action. Molecular Endocrinology, 22, 1552-1564.

https://doi.org/10.1210/me.2007-0570

[59] Kim, S.B., Awais, M., Sato, M., Umezawa, Y. and Tao, H. (2007)Integrated Molecule-Format Bioluminescent Probe for Visualizing Androgenicity of Ligands Based on the Intramolecular Association of Androgen Receptor with Its Recognition Peptide. Analytical Chemistry, 79, 1874-1880. https://doi.org/10.1021/ac061934u

[60] Kim, S.B., Umezawa, Y., Kanno, K.A. and Tao, H. (2008) An Integrated Molecule-Format Multicolor Probe for Monitoring Multiple Activities of a Bioactive Small Molecule. ACS Chemical Biology, 3, 359-372. https://doi.org/10.1021/cb800004s

[61] Paulmurugan, R., Tamrazi, A., Massoud, T.F., Katzenellenbogen, J.A. and Gambhir, S.S. (2011) In Vitro and in Vivo Molecular Imaging of Estrogen Receptor $\alpha$ and $\beta$ Homo- and Heterodimerization: Exploration of New Modes of Receptor Regulation. Molecular Endocrinology, 25, 2029-2040.

https://doi.org/10.1210/me.2011-1145

[62] Fan-Minogue, H., Cao, Z., Paulmurugan, R., Chan, C.T., Massoud, T.F., Felsher, D.W. and Gambhir, S.S. (2010) Noninvasive Molecular Imaging of c-Myc Activation in Living Mice. Proceedings of the National Academy of Sciences of the United States of America, 107, 15892-15897. https://doi.org/10.1073/pnas.1007443107

[63] Dang, C.V., O’Donnell, K.A., Zeller, K.I., Nguyen, T., Osthus, R.C. and Li, F. (2006) The c-Myc Target Gene Network. Seminars Cancer Biology, 16, 253-264. 
https://doi.org/10.1016/j.semcancer.2006.07.014

[64] Ilagan, M.X.G., Lim, S., Fulbright, M., Piwnica-Worms, D. and Kopan, R. (2011) Real-Time Imaging of Notch Activation with a Luciferase Complementation-Based Reporter. Science Signaling, 4, rs7. https://doi.org/10.1126/scisignal.2001656

[65] Kopan, R. and Ilagan, M.X.G. (2009) The Canonical Notch Signaling Pathway: Unfolding the Activation Mechanism. Cell, 137, 216-233.

https://doi.org/10.1016/j.cell.2009.03.045

[66] Macdonald-Obermann, J.L., Piwnica-Worms, D. and Pike, L.J. (2012) Mechanics of EGF Receptor/ErbB2 Kinase Activation Revealed by Luciferase Fragment Complementation Imaging. Proceedings of the National Academy of Sciences of the United States of America, 109, 137-142. https://doi.org/10.1073/pnas.1111316109

[67] Yang, K.S., Ilagan, M.X.G., Piwnica-Worms, D. and Pike, L.J. (2009) Luciferase Fragment Complementation Imaging of Conformational Changes in the Epidermal Growth Factor Receptor. Journal of Biological Chemistry, 284, 7474-7482. https://doi.org/10.1074/jbc.M808041200

[68] Misawa, N., Kafi, A., Hattori, M., Miura, K., Masuda, K. and Ozawa, T. (2010) Rapid and High-Sensitivity Cell-Based Assays of Protein-Protein Interactions Using Split Click Beetle Luciferase Complementation: An Approach to the Study of G-Protein-Coupled Receptors. Analytical Chemistry, 82, 2552-2560. https://doi.org/10.1021/ac100104q

[69] Hattori, M., Tanaka, M., Takakura, H., Aoki, K., Miura, K., Anzai, T. and Ozawa, T. (2013) Analysis of Temporal Patterns of GPCR- $\beta$-Arrestin Interactions Using Split Luciferase-Fragment Complementation. Molecular Biosystems, 9, 957-964. https://doi.org/10.1039/c2mb25443c

[70] Wolf, F., Li, W., Li, F. and Li, C.-Y. (2011)Novel Luciferase-Based Reporter System to Monitor Activation of ErbB2/Her2/neu Pathway Noninvasively during Radiotherapy. International Journal of Radiation Oncology, Biology, Physics, 79, 233-238. https://doi.org/10.1016/j.ijrobp.2010.08.001

[71] Yu, S.W., Wang, H.M., Poitras, M.F., Coombs, C., Bowers, W.J., Federoff, H.J., Poirier, G.G., Dawson, T.M. and Dawson, V.L. (2002) Mediation of Poly(ADP-Ribose) Polymerase-1-Dependent Cell Death by Apoptosis-Inducing Factor. Science, 297, 259-263. https://doi.org/10.1126/science.1072221

[72] Furman, J.L., Mok, P.-W., Shen, S., Stains, C.I. and Ghosh, I. (2010) A Turn-on Split-Luciferase Sensor for the Direct Detection of Poly(ADP-Ribose) as a Marker for DNA Repair and Cell Death. Chemical Communications, 47, 397-399. https://doi.org/10.1039/C0CC02229B

[73] Eustermann, S., Brockmann, C., Mehrotra, P.V., Yang, J.C., Loakes, D., West, S. C., Ahel, I. and Neuhaus, D. (2010) Solution Structures of the Two PBZ Domains from Human APLF and Their Interaction with Poly(ADP-Ribose). Nature Structral \& Molecular Biology, 17, 241-243. https://doi.org/10.1038/nsmb.1747

[74] Spencer, D.M., Wandless, T.J., Schreiber, S.L. and Crabtree, G.R. (1993) Controlling Signal Transduction with Synthetic Ligands. Science, 262, 1019-1024.

https://doi.org/10.1126/science.7694365

[75] Fegan, A., White, B., Carlson, J.C.T. and Wagner, C.R. (2010) Chemically Controlled Protein Assembly: Techniques and Applications. Chemical Reviews, 110, 3315-3336. https://doi.org/10.1021/cr8002888

[76] Spencer, D.M., Belshaw, P.J., Chen, L., Ho, S.N., Randazzo, F., Crabtree, G.R. and Schreiber, S.L. (1996) Functional Analysis of Fas Signaling in Vivo Using Synthetic 
Inducers of Dimerization. Current Biology, 6, 839-847. https://doi.org/10.1016/S0960-9822(02)00607-3

[77] Nyanguile, O., Uesugi, M., Austin, D.J. and Verdine, G.L. (1997) A Nonnatural Transcriptional Coactivator. Proceedings of the National Academy of Sciences of the United States of America, 94, 13402-13406.

https://doi.org/10.1073/pnas.94.25.13402

[78] Cheng, J.K., Yu, L., Zhang, D.Y., Huang, Q.J., Spencer, D. and Su, B. (2005) Dimerization through the Catalytic Domain Is Essential for MEKK2 Activation. Journal of Biological Chemistry, 280, 13477-13482. https://doi.org/10.1074/jbc.M414258200

[79] Freiberg, R.A., Spencer, D.M., Choate, K.A., Peng, P.D., Schreiber, S.L., Crabtree, G.R. and Khavari, P.A. (1996) Specific Triggering of the Fas Signal Transduction Pathway in Normal Human Keratinocytes. Journal Biological Chemistry, 271, 31666-31669. https://doi.org/10.1074/jbc.271.49.31666

[80] Schwartz, E.C., Saez, L., Young, M.W. and Muir, T.W. (2007) Post-Translational Enzyme Activation in an Animal via Optimized Conditional Protein Splicing. Nature Chemical Biology, 3, 50-54. https://doi.org/10.1038/nchembio832

[81] Mootz, H.D., Blum, E.S., Tyszkiewicz, A.B. and Muir, T.W. (2003) Conditional Protein Splicing: A New Tool to Control Protein Structure and Function in Vitro and in Vivo. Journal of the American Chemical Society, 125, 10561-10569.

https://doi.org/10.1021/ja0362813

[82] Mootz, H.D. and Muir, T.W. (2002) Protein Splicing Triggered by a Small Molecule. Journal of the American Chemical Society, 124, 9044-9045. https://doi.org/10.1021/ja026769o

[83] Sakamoto, K.M., Kim, K.B., Kumagai, A., Mercurio, F., Crews, C.M. and Deshaies, R.J. (2001) Protacs: Chimeric Molecules that Target Proteins to the Skp1-Cullin-F Box Complex for Ubiquitination and Degradation. Proceedings of the National Academy of Sciences of the United States of America, 98, 8554-8559. https://doi.org/10.1073/pnas.141230798

[84] Schneekloth, A.R., Pucheault, M., Tae, H.S. and Crews, C.M. (2008) Targeted Intracellular Protein Degradation Induced by a Small Molecule: En Route to Chemical Proteomics. Bioorganic \& Medicinal Chemistry Letter, 18, 5904-5908. https://doi.org/10.1016/j.bmcl.2008.07.114

[85] Pratt, M.R., Schwartz, E.C. and Muir, T.W. (2007) Small-Molecule-Mediated Rescue of Protein Function by an Inducible Proteolytic Shunt. Proceedings of the National Academy of Sciences of the United States of America, 104, 11209-11214. https://doi.org/10.1073/pnas.0700816104

[86] Hunter, T. (1995) Protein Kinases and Phosphatases: The Yin and Yang of Protein Phosphorylation and Signaling. Cell, 80, 225-236.

https://doi.org/10.1016/0092-8674(95)90405-0

[87] Manning, G., Whyte, D.B., Martinez, R., Hunter, T. and Sudarsanam, S. (2002) The Protein Kinase Complement of the Human Genome. Science, 298, 1912-1934. https://doi.org/10.1126/science.1075762

[88] Alonso, A., Sasin, J., Bottini, N., Friedberg, I., Friedberg, I., Osterman, A., Godzik, A., Hunter, T., Dixon, J. and Mustelin, T. (2004) Protein Tyrosine Phosphatases in the Human Genome. Cell, 117, 699-711. https://doi.org/10.1016/j.cell.2004.05.018

[89] Camacho-Soto, K., Castillo-Montaya, J., Tye, B.W. and Ghosh, I. (2014) Ligand-Gated Split-Kinases. Journal of the American Chemical Society, 136, 3995-4002. https://doi.org/10.1021/ja4130803 
[90] Camacho-Soto, K., Castillo-Montaya, J., Tye, B.W., Ogunleye, L.O. and Ghosh, I. (2014) Small Molecule Gated Split-Tyrosine Phosphatases and Orthogonal Split-Tyrosine Kinases. Journal of the American Chemical Society, 136, 17078-17086.

https://doi.org/10.1021/ja5080745 